\title{
A Controladoria como um Mecanismo Interno de Governança Corporativa: Evidências de uma Survey Comparativa entre Empresas de Capital Brasileiro e Norte-Americano
}

\begin{abstract}
Auster Moreira Nascimento Doutorado em Controladoria e Contabilidade pela Universidade de São Paulo - USP Professor da Universidade do Vale do Rio dos Sinos - UNISINOS

E-mail: auster@unisinos.br

Márcia Bianchi Mestrado em Ciências Contábeis pela Universidade do Vale do Rio dos Sinos UNISINOS Professora da Universidade Federal do Rio Grande do Sul - UFRGS E-mail:marcia.bianchi@ufrgs.br

Paulo Renato Soares Terra Doutorado em Administração - McGill University (Montreal, Canadá) Professor da Universidade Federal do Rio Grande do Sul - UFRGS E-mail: prsterra@ea.ufrgs.br
\end{abstract}

\section{RESUMO}

Esta pesquisa buscou verificar se as relações funcionais mantidas entre o controller de uma subsidiária ou filial de uma empresa e o seu gerente geral local (ou função equivalente), permitem sua atuação independente no processo de elaboração e divulgação das informações decorrentes dos atos administrativos e operacionais da unidade de negócios em que atua. A verificação ocorreu através de pesquisa de campo realizada com o uso de questionários respondidos por executivos de 66 empresas, sendo 35 brasileiras e 31 norte-americanas, cujos dados coletados foram tratados estatisticamente. Como principal conclusão tem-se que a área de controladoria: (a) pode ser considerada como um mecanismo interno de governança corporativa; (b) amplia a segurança dos usuários das informações sobre a empresa; (c) proporciona a divulgação dos atos de sua administração com a transparência requerida; (d) possibilita a redução da assimetria informacional e a minimização dos conflitos de agência; (e) monitora o processo de gestão e de manutenção dos sistemas de controle que o apóiam.

Palavras-chave: Teoria da Agência. Governança Corporativa. Processo de Gestão. Dimensões de Controle. Controladoria. a Comparative Survey of Brazilian versus North American-Owned Firms 
A Controladoria como um Mecanismo Interno de Governança Corporativa: Evidências de uma Survey Comparativa entre Empresas de Capital Brasileiro e Norte-Americano Auster Moreira Nascimento, Márcia Bianchi, Paulo Renato Soares Terra

\section{ABSTRACT}

This research aimed to identify whether the functional relationships between a controller of a company's business unit or subsidiary and his/her local general manager or equivalent allows him/her to perform his/her work with independence. Focus is on the process of reporting administrative and operational issues regarding the business unit they both work for. The controller reassures to owners or their direct representatives the transparency in the use of company resources by management, thus qualifying him/her as a complementary instrument of corporate governance. Field research was carried out through the administration of questionnaires to executives of 66 companies (35 Brazilian companies and 31 North American ones). Such data was collected and statistically analyzed, leading to the conclusion that the control department may be considered an internal mechanism of corporate governance because it reassures the disclosure of managerial acts and has the potential to reduce information asymmetry and to minimize agency conflicts.

Keywords: Agency Theory. Corporate Governance. Management Process. Dimensions of Control. Controlling.

\section{INTRODUÇÃO}

Desde a revolução industrial, o progresso social resultante vem estimulando mudanças na forma de gestão das organizações. As empresas, à medida que se desenvolvem, tendem a ser administradas não somente pelos seus proprietários, membros de sua família ou outros indivíduos cujos vínculos pessoais com o proprietário podem transcender suas capacidades de gestão.

A mudança do perfil da administração, quanto à sua gestão, é uma resposta da organização para a necessidade de se manter ou se tornar eficaz.

A insegurança natural existente entre o principal e o agente é o combustível que alimenta os conflitos intrínsecos a essa relação, gerando a necessidade de se criarem mecanismos que revistam as operações da organização com a segurança necessária para que a integridade de seus resultados seja preservada e as transações que os formam sejam conduzidas com eficácia e transparência. Essa preocupação incentiva a adoção de uma estratégia para o comportamento administrativo que considere um alinhamento entre os objetivos do principal e do agente o que pode ocorrer, por exemplo, através de remuneração adequada ao agente para que este exerça suas funções de forma congruente com os objetivos do principal, combinada com 
A Controladoria como um Mecanismo Interno de Governança Corporativa: Evidências de uma Survey Comparativa entre Empresas de Capital Brasileiro e Norte-Americano Auster Moreira Nascimento, Márcia Bianchi, Paulo Renato Soares Terra

mecanismos de recompensa que os estimulem a produzirem resultados sempre eficazes quando do exercício de suas atividades.

Uma administração ideal, em que os recursos da empresa são administrados com eficácia e os interesses de todos envolvidos em sua administração são preservados em equilíbrio, encontra suas bases no modelo de gestão, materializado no processo de gestão, cujos mecanismos devem assegurar a sua eficácia e controlabilidade e, em consequência, propiciar a redução de conflitos entre o principal e o agente. Entre os vários elementos componentes desse processo destacam-se: o planejamento empresarial e suas diversas fases, bem como as bases de controle que as sustentam.

Entretanto, o planejamento e seus desdobramentos, em si, pode ser somente um instrumento inanimado de administração e não servir ao propósito de diminuição dos conflitos entre principal e agente. Para ser de fato útil como uma ferramenta de gestão, ele deve apoiar-se em uma estrutura de controles internos que permita o estreito monitoramento do uso dos recursos operacionais requeridos para a sua execução e para o apontamento das razões que eventualmente gerem desvios dos resultados realizados, contrapostos às expectativas do dono do negócio quando da sua elaboração e aprovação.

É nesse contexto que a área de controladoria de uma empresa, para cumprir sua missão, deve representar um papel central na mediação dos conflitos entre seu principal e seus agentes. Além de ser sua a função de manutenção do sistema de controles internos, estabelecidos para a proteção dos ativos organizacionais, a essa área cabe também a tarefa de auxiliar na construção do sistema de informações econômico-financeiras da organização e sobre ele exercer controle.

Dessa área devem surgir, também, iniciativas visando a acompanhar os controles organizacionais em todas as suas dimensões, os quais podem proporcionar não apenas decisões úteis para o processo de gestão, como outras decisões cuja integridade assegure aos investidores (principais) que os recursos necessários às operações estejam sendo consumidos de forma congruente com os objetivos que eles, os investidores, estabeleceram. Em outras palavras, espera-se da área de controladoria uma postura de defesa dos interesses dos proprietários da organização ou, quando for 
A Controladoria como um Mecanismo Interno de Governança Corporativa: Evidências de uma Survey Comparativa entre Empresas de Capital Brasileiro e Norte-Americano Auster Moreira Nascimento, Márcia Bianchi, Paulo Renato Soares Terra

o caso, daqueles que os representam diretamente na gestão do empreendimento.

Diante do exposto, o objetivo geral deste estudo é verificar se as relações funcionais entre o controller de uma subsidiária ou filial de uma empresa e o seu gerente geral local ou função equivalente permitem independência ao controller no processo de elaboração e divulgação das informações decorrentes dos atos administrativos e operacionais da unidade de negócios para a qual trabalha.

Para atingir esse objetivo assume-se como premissa que os fatores determinantes para a mencionada independência são, entre outros não pesquisados: a subordinação hierárquica, a fonte que autoriza aumentos salariais espontâneos, a responsabilidade pela contratação, promoção ou demissão do controller e a autoridade para atualizar e modificar os relatórios contábeis.

Este artigo contribui tanto para o meio acadêmico como para o profissional. Primeiro, por buscar na teoria os elementos comuns entre controladoria e governança corporativa; segundo, por investigar empiricamente um universo de empresas em atividade no Brasil. Finalmente, este artigo contribui ao comparar a experiência das subsidiárias de empresas norte-americanas com aquela das empresas brasileiras, fato que proporciona novos insights sobre essa questão.

\section{REFERENCIAL TEÓRICO}

\subsection{Teoria da Agência e Governança Corporativa}

Enquanto as empresas são controladas e administradas por seus próprios donos, desde que seu porte assim o permita, a propriedade e o controle da organização estão centralizados no mesmo indivíduo, isto é, no proprietário. À medida que as organizações se desenvolvem, tornando-se mais complexas, dado o crescimento de suas operações, surge a necessidade de delegação do controle pelo proprietário aos administradores para tal remunerados.

A essência deste princípio é que levou às investigações que culminaram na chamada Teoria da Agência, cuja investigação iniciou a partir do estudo de Adolph Berle e Gardiner Means, documentado em sua obra "A Moderna Sociedade Anônima e a Propriedade Privada" em 1932. 
A Controladoria como um Mecanismo Interno de Governança Corporativa: Evidências de uma Survey Comparativa entre Empresas de Capital Brasileiro e Norte-Americano Auster Moreira Nascimento, Márcia Bianchi, Paulo Renato Soares Terra

Berle e Means (1984, p. 3) retrataram em sua obra que a parte da riqueza industrial individual de um país havia se deslocado para grandes empresas financiadas pelo público, o que transformou a vida dos proprietários e dos trabalhadores e as formas de propriedade. "O divórcio entre a propriedade e o controle, resultante desse processo, envolve quase necessariamente uma nova forma de organização econômica da sociedade. "

Anos mais tarde, Coase (1937) abordou de forma pioneira a natureza da firma, no que se refere à consideração dos aspectos internos da empresa, enfatizando a imagem do empreendedor como a figura-chave para a alocação correta de recursos no processo de tomada de decisões e tratando das questões contratuais nas quais estão envolvidas as firmas, que são vistas como consequência de contratos implícitos (parcerias informais) e explícitos (contratos formais de trabalho) que são estabelecidos entre agentes, como trabalhadores, executivos e clientes.

O raciocínio iniciado por Coase (1937) foi seguido por Alchian e Demsetz (1972), e posteriormente por Jensen e Meckling (1976), que o aperfeiçoaram. Alchian e Demsetz (1972) abordaram a natureza da firma, estabelecendo que a noção das atividades internas da empresa deveria estar fundamentada em um conjunto de relações contratuais entre os indivíduos da organização, concordando com Coase no que se refere à função dos contratos, que é relatar todos os direitos e deveres das pessoas que participam de uma organização.

Jensen e Meckling (1976) fizeram uma análise das implicações comportamentais provenientes dos direitos especificados nos contratos entre os proprietários e os administradores da empresa. Os autores argumentam que

é importante reconhecer que a maioria das organizações são simplesmente ficções legais as quais servem como um nexo para um conjunto de relações contratuais entre indivíduos [...] A corporação privada ou firma é simplesmente uma forma de ficção legal a qual serve como um foco para um complexo processo no qual os objetivos conflitantes dos indivíduos são colocados em equilíbrio dentro de uma estrutura de relações contratuais (Jensen e Meckling, 1976, p. 305).

A partir dessa premissa, a Teoria da Agência foi apresentada pelos autores de 
A Controladoria como um Mecanismo Interno de Governança Corporativa: Evidências de uma Survey Comparativa entre Empresas de Capital Brasileiro e Norte-Americano Auster Moreira Nascimento, Márcia Bianchi, Paulo Renato Soares Terra

forma mais abrangente, dando maior ênfase à separação entre a propriedade e o controle de uma empresa.

Em decorrência da separação da propriedade e do controle da empresa ocorrem profundas mudanças na forma de gerenciá-la, visto que os administradores, os agentes, tendem a considerar nas tomadas de decisões não apenas o interesse do proprietário, o principal, mas também seus próprios interesses.

Williamson (1985), quando se refere à Teoria da Agência, menciona que ela trata das relações contratuais, onde incentivos e controles são fundamentais. Tais incentivos e controles são decorrentes do modelo de gestão organizacional, que estabelece a forma como a organização vai ser administrada, premiando ou punindo seus gestores a partir de um processo de gestão que, fundamentalmente, retrata quais e como os resultados devem ser obtidos, pressupondo a existência de uma área que atue com neutralidade no monitoramento desse processo, que, devido a sua missão, supõe-se ser esta área a de controladoria

A área de controladoria pode contribuir com a Teoria da Agência pelo fato de poder monitorar um sistema de informação, de mensuração de resultados e reportar suas observações ao principal e, também, ao agente, proporcionando a este o conhecimento de suas contribuições para o resultado organizacional, contrapondo-se ao que dele se espera, uma vez que fornece informações relevantes ao principal sobre as ações dos agentes, informações sobre dados históricos e a probabilidade de ocorrências futuras.

Saliente-se que um dos objetivos da Teoria da Agência é a eficiência dos contratos, o que simultaneamente reduz os custos de agência. Entende-se que a controladoria, através de seus relatórios que fornecem informações importantes para tomar decisões estratégicas, e que, em consequência, afetam o processo decisório, possibilitando a obtenção de níveis de eficácia no resultado econômico, além de fomentar a transparência nas ações dos gestores, contribui com a Teoria da Agência para a redução dos custos de agência.

Ressalte-se que há outros fatores de forte influência nos custos de transação como um todo e que estão implícitos em quaisquer das abrangências dadas ao problema de agência, que são a assimetria de informação, influenciada pelo risco moral 
A Controladoria como um Mecanismo Interno de Governança Corporativa: Evidências de uma Survey Comparativa entre Empresas de Capital Brasileiro e Norte-Americano Auster Moreira Nascimento, Márcia Bianchi, Paulo Renato Soares Terra

e pela seleção adversa.

A assimetria de informação também pode ocorrer quando o proprietário possui dificuldades para observar todas as ações do administrador; essas ações podem ser diferentes das ações que ele teria escolhido. O administrador pode ter tomado determinadas ações consideradas pelo principal como não adequadas por possuir princípios próprios, preferências diferentes por riscos ou até mesmo por intenção deliberada de agir contra o proprietário e em benefício próprio, isto é, por má índole.

Essa situação cria o que é conhecido como risco moral (moral hazard). De acordo com Milgrom e Roberts (1992), o risco moral é uma forma de oportunismo que surge depois que é efetivado um contrato, porque atitudes que possuem diferentes premissas não são livremente observáveis e então as pessoas que as tomam podem buscar seus próprios interesses às expensas dos interesses de outro. Os autores enfatizam ainda que o risco moral é um fenômeno muito comum nas organizações.

A prática da governança corporativa, se insere no contexto da busca de fortalecimento do mercado acionário à medida que objetiva minimizar os potenciais conflitos de interesse existentes entre os acionistas majoritários e os minoritários, isto é, entre os proprietários e os administradores, como, também, entre os demais agentes da empresa, tendo como objetivo principal a maximização do valor da organização e, consequentemente, maior retorno para os acionistas ou proprietários. Resumindo, a governança corporativa tem como principal finalidade minimizar os problemas de agência entre os diversos atores da relação empresarial.

A governança corporativa é um conjunto de mecanismos que serve para monitorar através desse controle, a gestão e o desempenho das organizações; ou, ainda, pode ser definida como uma forma de esforço contínuo em alinhar os objetivos da alta administração aos interesses dos acionistas ou proprietários, por meio da adoção de práticas mais eficazes de monitoramento.

Lodi (2000) define a governança corporativa como o sistema de relacionamento entre os acionistas, os auditores independentes, os executivos da empresa e os conselheiros de administração.

Corroborando com essa afirmativa, o IBGC (2004) define governança corporativa como sendo 
A Controladoria como um Mecanismo Interno de Governança Corporativa: Evidências de uma Survey Comparativa entre Empresas de Capital Brasileiro e Norte-Americano Auster Moreira Nascimento, Márcia Bianchi, Paulo Renato Soares Terra

o sistema que assegura aos sócios-proprietários o governo estratégico da empresa e a efetiva monitoração da diretoria executiva. A relação entre propriedade e gestão se dá através do conselho de administração, a auditoria independente e o conselho fiscal, instrumentos fundamentais para o exercício do controle. A boa Governança Corporativa assegura aos sócios equidade, transparência, responsabilidade pelos resultados (accountability) e obediência às leis do país (compliance).

A Comissão de Valores Mobiliários - CVM define governança corporativa como sendo

o conjunto de práticas que tem por finalidade otimizar o desempenho de uma companhia ao proteger todas as partes interessadas, tais como investidores, empregados e credores, facilitando o acesso ao capital. A análise das práticas de governança corporativa aplicada ao mercado de capitais envolve, principalmente: transparência, equidade de tratamento dos acionistas e prestação de contas (CVM, 2002, p. 1).

À primeira vista, devido ao envolvimento da CVM e de outros órgãos reguladores, fica a impressão de que o conceito de governança corporativa seja aplicável apenas às empresas que negociam em bolsas de valores, isto é, apenas aquelas cujo capital é aberto. Sabe-se, entretanto, que num sentido amplo a governança corporativa deve ser entendida como um conjunto de mecanismos e atitudes que reveste de transparência as operações de uma organização sob o ponto de vista de quem quer que esteja por ela interessado.

De acordo com Almeida (2001), tradicionalmente a governança corporativa se preocupou em resolver os conflitos de interesse entre administradores e proprietários. Entretanto, os conflitos de interesse ocorrem entre uma gama mais ampla de agentes, os stakeholders: acionistas minoritários, acionistas majoritários, credores, gerentes, empregados, consumidores e sociedade como um todo. Assim, a governança corporativa possui como desafio minimizar os potenciais conflitos de interesse entre esses agentes.

Existem vários mecanismos que podem ser utilizados pelo principal para dirigir seus agentes e assegurar que eles cumpram suas responsabilidades. Hitt, Ireland e 
A Controladoria como um Mecanismo Interno de Governança Corporativa: Evidências de uma Survey Comparativa entre Empresas de Capital Brasileiro e Norte-Americano Auster Moreira Nascimento, Márcia Bianchi, Paulo Renato Soares Terra

Hoskisson (2003) citam quatro mecanismos internos de governança e apenas um mecanismo externo, que são utilizados na moderna corporação.

Os quatro aqui examinados são: a concentração de propriedade, representada pelos tipos de acionistas e seus diferentes incentivos para monitorar os agentes, o Conselho de Administração, a remuneração executiva e a estrutura da organização multidivisional. Em seguida, consideramos o mercado para controle corporativo um mecanismo externo de controle corporativo (Hitt; Ireland; Hoskisson, 2003, p. 405).

Poder-se-ia acrescer aos mencionados quatro mecanismos internos a área de controladoria, pois nada garantiria a existência de níveis de governança se o ambiente e o controle interno da organização não permitissem a existência de informações acuradas, sendo esse elemento o que pauta a existência da mencionada área.

Conforme Becht, Bolton e Röell (2002, p. 10), a governança corporativa está em evidência atualmente, sem uma ordem específica, devido às seguintes razões: a onda de privatização de amplitude mundial nas últimas duas décadas; a reforma dos fundos de pensão e o crescimento da poupança privada; a onda de takeover dos anos 1980; a desregulamentação e a integração do mercado de capitais; a crise da Ásia Oriental de 1998, que colocou em evidência a governança corporativa em mercados emergentes; e uma série de escândalos americanos e falências corporativas que se formaram, mas que não apareceram durante a era do mercado agressivo da última parte da década de 1990.

\subsection{Governança Corporativa e Controladoria}

A essência do conceito de governança corporativa envolve a transparência na administração e os meios por ela utilizados para a redução, tanto quanto possível, da assimetria informacional existente entre aqueles que geram a informação e aqueles que a utilizam.

A governança corporativa também se relaciona à existência de mecanismos específicos de controle que transmitem segurança aos interessados no resultado da organização quanto ao correto manuseio dos recursos colocados à disposição de seus gestores no processo de obtenção de receitas, no sentido de que os necessários 
A Controladoria como um Mecanismo Interno de Governança Corporativa: Evidências de uma Survey Comparativa entre Empresas de Capital Brasileiro e Norte-Americano Auster Moreira Nascimento, Márcia Bianchi, Paulo Renato Soares Terra

sacrifícios de ativos, sejam esses financeiros ou de outra natureza, sejam plenamente recompensados à luz dos resultados alcançados.

Os mecanismos de governança preconizados por instituições que defendem a transparência administrativa, como o IBGC, podem não garantir, entretanto, que ela exista nos níveis necessários. Isso porque os referidos mecanismos não implicam envolvimento operacional daqueles que os personificam, de tal forma que dependem de outros aspectos internos nas organizações para atingir os propósitos a que se propõem. Estes pavimentam a base que lhes permitam ser eficazes na sua missão de promover a igualdade informacional e a redução do conflito de interesses entre as partes interessadas pela performance organizacional. Portanto, cabe às empresas criarem estrutura e instrumento que viabilizem atender ao estabelecido pelo IBGC.

Por exemplo, a existência de conselho de administração e de auditoria independente, tidos como indicadores de boas práticas de governança corporativa, podem não garantir que as melhores decisões sejam tomadas pelos gestores ou que todos os registros de operações da empresa reflitam de forma íntegra o que de fato ocorreu. Isso porque os citados mecanismos têm limites naturais que os impedem de enxergar todos os ângulos de uma transação ou atividade, desenvolvida no complexo sistema empresa, e de analisar com completa segurança as informações a elas correspondentes, podendo o fruto dessa análise atingir apenas parcialmente seus objetivos.

Essa limitação é uma consequência natural do fato de que os defensores das boas práticas de governança não atuam de forma plena no palco onde se desenvolvem as operações da empresa e no qual são geradas todas as informações que eventualmente pudessem Ihes interessar. Ou seja, suas atuações esbarram em limitações físicas para compreender se há problemas na gestão, causados por desvio de conduta ou falta de habilidade dos gestores, pelo simples fato de não estarem cotidianamente participando de cada decisão ou de cada registro de informação na organização.

Dessa forma, acredita-se que as práticas de governança corporativa deveriam ser norteadas principalmente por controles que permitam aos interessados pela empresa concluírem de forma mais segura sobre a existência ou não de transparência 
A Controladoria como um Mecanismo Interno de Governança Corporativa: Evidências de uma Survey Comparativa entre Empresas de Capital Brasileiro e Norte-Americano Auster Moreira Nascimento, Márcia Bianchi, Paulo Renato Soares Terra

nos atos de sua administração, bem como garantias mínimas de que os conflitos de interesse de gestores que tanto se busca combater, mas que persistem e são um dos responsáveis pela indesejável falta de transparência, não interfiram na capacidade organizacional de obtenção de resultados econômicos.

Assim, o controle organizacional, num sentido amplo, é a peça-chave para a discussão envolvendo governança corporativa. Nesse contexto torna-se oportuno o debate sobre as funções da área de controladoria, que tem como uma de suas atribuições a manutenção do sistema de controles internos da empresa, que é a plataforma dos sistemas de informações, instrumentos de gestão e de controle operacional que fomentam a eficácia organizacional, via tomada de decisões acertadas e a segurança dos ativos envolvidos nesse processo.

As empresas procuram subsídios na área de controladoria para se tornar mais competitivas e organizadas. Competitivas no sentido de que faz parte da missão dessa área fornecer aos gestores informações precisas para subsidiar o processo decisório (Tung, 1993), além de organizadas, pois a ela também se atribui a responsabilidade de estabelecer, implementar e monitorar o sistema de controles internos necessários para a salvaguarda de ativos e para a manutenção da integridade dos registros contábeis.

Nesse contexto, a essência da palavra controle é ampla, e para melhor entendêla deve-se examiná-la sob a perspectiva das dimensões em que ela é constituída, sendo estas, por sua vez, caracterizadas pelos níveis de importância que os controles têm para o processo de formação de resultados econômicos e para a transparência administrativa quanto aos meios utilizados para a sua obtenção. Para os fins dessa pesquisa, classificam-se essas dimensões de controle em: operacional, físico-financeira e prescritiva, como destacado na figura 1 apresentada a seguir. 


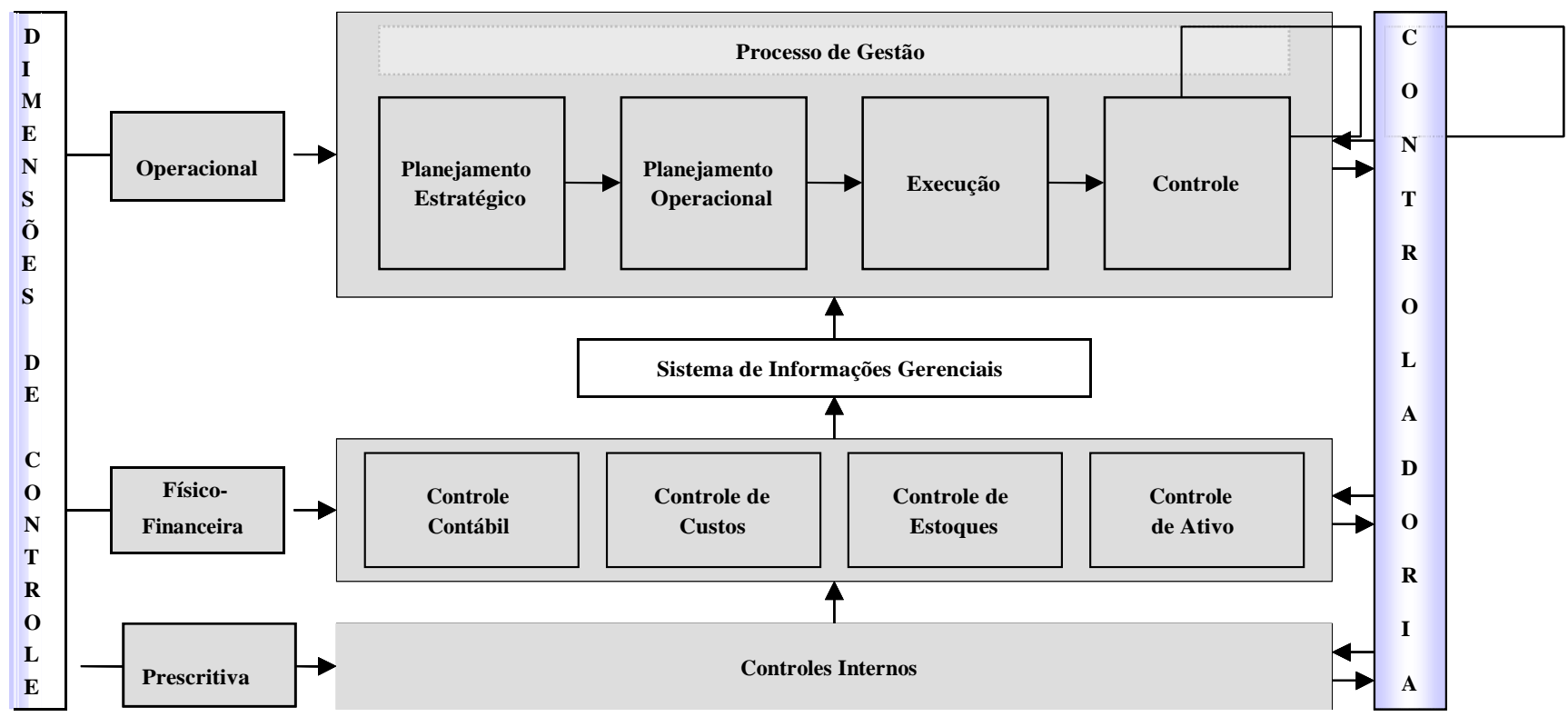

Figura 1 - Visão Dimensional do Controle Organizacional

A dimensão de controle operacional é representada pela sinergia dos meios colocados à disposição dos administradores para o contínuo acompanhamento do comportamento da organização frente às mudanças ambientais, e para instrumentalizálos no processo de tomada de decisões requeridas para os ajustes das atividades operacionais às condições observadas, reorientando-as, quando necessário, para a preservação dos objetivos traçados pela empresa.

Os mencionados meios materializam-se através do processo de gestão, que, de acordo com Catelli et al., (2001), é estruturado nas fases de planejamento estratégico, de planejamento operacional, de execução e de controle

Essa dimensão de controle operacional é importante na redução de conflitos e também sob o ponto de vista da governança corporativa, porque permite estabelecer o que se espera do gestor, criando um ponto de referência para a alta administração entender se o gestor é eficaz no manuseio dos recursos. Entretanto, essa etapa depende de informações acuradas, tempestivas e íntegras, que são os produtos da segunda dimensão de controle: a físico- financeira.

A dimensão de controle físico-financeira pode ser definida como aquela voltada para o registro e o controle de todos os eventos que tenham repercussão econômica para 


\section{A Controladoria como um Mecanismo Interno de Governança Corporativa: Evidências de uma Survey Comparativa entre Empresas de Capital Brasileiro e Norte-Americano}

Auster Moreira Nascimento, Márcia Bianchi, Paulo Renato Soares Terra

uma organização.

É a esfera administrativa onde deve ser possível obter-se explicações detalhadas sobre qualquer dado ou fato que justifique o resultado econômico decorrente da utilização de um determinado recurso da empresa, tanto em nível global como em nível de área de responsabilidade. Conceitua-se essa dimensão de controle como aquela que supre as atividades operacionais com o nível de informação necessário para a irrigação da ação decisorial através de informações oportunas, completas e precisas que induzam à reflexão necessária para a obtenção de resultados otimizados.

Essa dimensão tem como característica o registro de cada transação econômica realizada na empresa. Compõe-se de sistemas de controle que cumprem funções mais amplas do que o simples armazenamento de dados: são as fontes das informações que permitem o rastreamento dos consumos dos recursos usados na operação e dos resultados decorrentes e, também, o suprimento dos gestores com as informações necessárias para o processo decisório.

Os atributos dessa dimensão de controle a tornam uma peça-chave para a manutenção da segurança dos ativos da empresa para a explicação e divulgação de seus resultados econômicos a todos aqueles por ela interessados. Por essa razão, pode-se considerá-la uma das bases para o alcance das melhores práticas de governança corporativa e, se apropriadamente conservada, como um dos fatores que possibilitam a redução de conflitos entre principal e agente.

Saliente-se que os sistemas da dimensão físico-financeira são alimentados pela ação humana, o que não permite afirmar que sejam infalíveis. Falhas em sua alimentação e manutenção ou erros intencionais podem comprometer a qualidade das informações que geram. A segurança e a confiabilidade dessas informações dependem da robustez e eficácia de uma outra dimensão de controle, a prescritiva.

A dimensão de controle prescritiva diz respeito ao conjunto das normas de procedimentos e de controles internos formais, estabelecido com o propósito de padronizar o comportamento administrativo em todos os seus níveis, buscando proporcionar meios seguros de acompanhamento das ações dos membros organizacionais, possibilitando o rastreamento de cada transação ocorrida no âmbito da empresa, que envolva tanto o consumo como o manuseio de seus ativos. Essa dimensão 
A Controladoria como um Mecanismo Interno de Governança Corporativa: Evidências de uma Survey Comparativa entre Empresas de Capital Brasileiro e Norte-Americano Auster Moreira Nascimento, Márcia Bianchi, Paulo Renato Soares Terra

abrange, ainda, as regras formais de conduta que devem nortear os gestores e seus colaboradores, quanto aos níveis ético e técnico, vistos como necessários para o exercício de suas funções.

É na dimensão de controle prescritiva que a empresa se apóia para assegurar a integridade das informações que compõem o banco dos dados armazenados pelos componentes da dimensão de controle físico-financeira, uma das principais fontes de informações, da qual se nutre o processo de gestão organizacional, desenvolvido na dimensão de controle operacional.

As normas de procedimento e outros mecanismos de controle interno são os elementos que integram todo o controle organizacional em um sentido amplo, formatando a dimensão prescritiva para que nessa se desenvolva um ambiente propício para a manutenção da transparência dos atos administrativos e de suas consequências. Isto é, os registros contábeis e os outros componentes da dimensão físico-financeira da empresa refletem informações sobre eventos que aconteceram. Mesmo que o façam de forma acurada, entretanto, não asseguram que todos os eventos ocorridos tenham sido, de fato, registrados. Por essa razão, essa instância de controle necessita de uma outra que a complemente, ampliando o seu alcance como ferramenta de governança corporativa e de monitoramento dos conflitos de agência. Essa instância complementar é a dimensão de controle prescritiva

\section{MÉTODO DE PESQUISA}

O universo de pesquisa são as empresas localizadas nos estados do Rio Grande do Sul, Santa Catarina, Paraná e São Paulo, que constam na revista Valor 1000 edição no ano de 2004. A amostra do estudo é do tipo amostragem simples, não aleatória, tendo em vista a viabilidade da pesquisa no que se refere à coleta dos dados. É composta por 96 empresas que atuam no setor industrial, possuem origem de capital brasileiro e norteamericano (dado fornecido pela revista) e possuem área de controladoria.

O estudo envolveu uma pesquisa de campo e o instrumento utilizado para a coleta dos dados foi um questionário, dirigido ao controller ou ao diretor financeiro, visando direcioná-lo ao responsável pelo fornecimento de informações à matriz ou à alta 
A Controladoria como um Mecanismo Interno de Governança Corporativa: Evidências de uma Survey Comparativa entre Empresas de Capital Brasileiro e Norte-Americano Auster Moreira Nascimento, Márcia Bianchi, Paulo Renato Soares Terra

administração. Para verificação sobre a clareza e precisão das questões e também das alternativas fixas de resposta, o questionário foi previamente submetido à um pré-teste, com dois controllers, cujas sugestões de melhorias foram incorporadas ao instrumento.

$\mathrm{Na}$ Tabela, a seguir, consta a amostra ajustada, refletindo apenas as empresas que se dispuseram a participar da pesquisa e o total das respostas consideradas para a análise:

Tabela 1 - Amostra Ajustada e Total de Respostas

\begin{tabular}{|c|c|c|c|}
\hline \multicolumn{4}{|c|}{ Origem do Capital } \\
\hline Situação & Brasileira & $\begin{array}{c}\text { Norte- } \\
\text { Americana }\end{array}$ & Total \\
\hline Total de empresas selecionadas para contato & $\begin{array}{c}48 \\
50 \% \\
\end{array}$ & $\begin{array}{c}48 \\
50 \% \\
\end{array}$ & $\begin{array}{c}96 \\
100 \% \\
\end{array}$ \\
\hline $\begin{array}{c}\text { Empresas que alegaram política de não responder a } \\
\text { pesquisas, não tinham o setor de controladoria ou não } \\
\text { atenderam aos telefonemas }\end{array}$ & $\begin{array}{c}6 \\
42,86 \% \\
\end{array}$ & $\begin{array}{c}8 \\
57,14 \% \\
\end{array}$ & $\begin{array}{c}14 \\
100 \% \\
\end{array}$ \\
\hline \multicolumn{4}{|l|}{ Amostra Ajustada } \\
\hline (empresas que aceitaram participar da pesquisa) & $\begin{array}{c}42 \\
51,22 \%\end{array}$ & $\begin{array}{c}40 \\
48,78 \% \\
\end{array}$ & $\begin{array}{c}82 \\
100 \%\end{array}$ \\
\hline Respostas não recebidas & $\begin{array}{c}3 \\
7,14 \% \\
\end{array}$ & $\begin{array}{c}8 \\
20,00 \% \\
\end{array}$ & $\begin{array}{c}11 \\
13,41 \% \\
\end{array}$ \\
\hline Total de Respostas & $\begin{array}{c}39 \\
92,86 \% \\
\end{array}$ & $\begin{array}{c}32 \\
80,00 \% \\
\end{array}$ & $\begin{array}{c}71 \\
86,58 \% \\
\end{array}$ \\
\hline Respostas desclassificadas & $\begin{array}{c}4 \\
9,52 \%\end{array}$ & $\begin{array}{c}1 \\
2,50 \% \\
\end{array}$ & $\begin{array}{c}5 \\
6,10 \% \\
\end{array}$ \\
\hline Total de Respostas Ajustada & $\begin{array}{c}35 \\
83,33 \%\end{array}$ & $\begin{array}{c}31 \\
77,50 \%\end{array}$ & $\begin{array}{c}66 \\
80,49 \%\end{array}$ \\
\hline
\end{tabular}

A desclassificação de algumas empresas (Tabela 1) se deu em razão dos questionários terem retornado incompletos, principalmente em relação às questões que permitiriam responder o objetivo do estudo. Mesmo após contatos feitos com os respondentes, não houve interesse por parte dos mesmos em complementar as questões não respondidas, bem como se recusaram a esclarecer dúvidas sobre as respostas que deram.

Para a aplicação dos testes estatísticos foi utilizado o software Statistical Package for Social Sciences (SPSS) for Windows, versão 12.0, do qual se obteve a distribuição de 
A Controladoria como um Mecanismo Interno de Governança Corporativa: Evidências de uma Survey Comparativa entre Empresas de Capital Brasileiro e Norte-Americano Auster Moreira Nascimento, Márcia Bianchi, Paulo Renato Soares Terra

frequências, testes qui-quadrado, para as questões que o requereram.

Segundo Stevenson (2001, p. 33), distribuição de frequência "é um grupamento de dados em classes, exibindo o número ou percentagem de observações em cada classe. Uma distribuição de frequência pode ser apresentada sob forma gráfica ou tabular".

O teste do qui-quadrado, segundo Rea e Parker (2002), consiste em medir a diferença entre as frequências esperadas e as de fato obtidas pelo processo de pesquisa, de acordo com a seguinte equação:

$$
\chi^{2}=\sum^{\left(f_{0}-f_{e}\right)^{2}}
$$

onde: fo é a frequência obtida em cada célula; e,

fe é a frequência esperada em cada célula na suposição da inexistência de diferença.

\section{ANÁLISE DOS DADOS}

\subsection{Item 1: Subordinação do controller}

O resultado da pesquisa aponta que o controller tem, na maioria dos casos, condições favoráveis para a execução de suas funções de forma independente da administração local, de cujo quadro ele diretamente faz parte. Como se observa na Tabela 2, apenas em $19 \%$ das empresas norte-americanas que são objeto da pesquisa o controller subordinase diretamente ao gerente geral local ou cargo equivalente. Tal tendência também pode ser constatada nas empresas brasileiras, onde a subordinação se dá em somente $6 \%$ dos casos.

Tabela 2 - Subordinação do Controller

\begin{tabular}{|c|c|c|}
\hline & Norte-Americana & Brasileira \\
\hline Gerente geral local ou equivalente & $19 \%$ & $6 \%$ \\
\hline Controller ou equivalente da matriz & $23 \%$ & $23 \%$ \\
\hline Gerente geral local e controller da matriz & $55 \%$ & $3 \%$ \\
\hline Principal executivo da corporação & $0 \%$ & $14 \%$ \\
\hline Outros & $3 \%$ & $54 \%$ \\
\hline Total & $\mathbf{1 0 0} \%$ & $\mathbf{1 0 0} \%$ \\
\hline
\end{tabular}


A Controladoria como um Mecanismo Interno de Governança Corporativa: Evidências de uma Survey Comparativa entre Empresas de Capital Brasileiro e Norte-Americano

Auster Moreira Nascimento, Márcia Bianchi, Paulo Renato Soares Terra

A pesquisa revela também que, em $55 \%$ dos casos das empresas norteamericanas pesquisadas, a relação funcional preferida para o controller é a sua subordinação a um executivo estabelecido diretamente na matriz e, concomitantemente, ao gerente geral, ou equivalente, da subsidiária, configurando-se, assim, uma estrutura matricial. É possível inferir que com a subordinação direta à matriz busca-se assegurar a transparência administrativa e, como decorrência, o nível de governança corporativa estabelecido pela matriz.

Em relação as respostas da pesquisa classificadas como outras, como se observa na Tabela 2, em 54\% das empresas brasileiras o controller reporta-se a um nível intermediário entre o seu e o do principal executivo da organização, como, por exemplo, diretor administrativo e financeiro. Seguindo o raciocínio anteriormente empregado, nesses casos o controller pode ter sua atuação comprometida quanto à sua isenção no ato de reportar os atos e fatos administrativos praticados até o limite de seu superior hierárquico.

\subsection{Item 2: Determinação dos aumentos salariais espontâneos para o controller}

Um dos fatores que poderiam refletir negativamente na atuação do controller, no que tange à sua capacidade de reduzir conflitos de interesse entre principal e agente, é a forma segundo a qual são definidos seus aumentos espontâneos de salário.

A pesquisa demonstrou, nas amostras analisadas, que nas empresas norteamericanas em apenas $26 \%$ dos casos o gerente geral local, ou função equivalente, é quem determina os aumentos espontâneos de salário para o controller, sendo isso uma decisão dependente de executivos estabelecidos na matriz. Já em $10 \%$ dos casos, classificados como "outros" na Tabela 3, os controllers têm aumentos espontâneos de seus salários, determinados por políticas preestabelecidas pela matriz. 
A Controladoria como um Mecanismo Interno de Governança Corporativa: Evidências de uma Survey Comparativa entre Empresas de Capital Brasileiro e Norte-Americano Auster Moreira Nascimento, Márcia Bianchi, Paulo Renato Soares Terra

Tabela 3 - Aumentos Salariais Espontâneos

\begin{tabular}{|c|c|c|}
\hline & Norte-Americana & Brasileira \\
\hline Gerente geral local ou equivalente & $26 \%$ & $11 \%$ \\
\hline Controller ou equivalente da matriz & $29 \%$ & $17 \%$ \\
\hline Gerente geral local e controller da matriz & $35 \%$ & $0 \%$ \\
\hline Principal executivo da corporação & $0 \%$ & $18 \%$ \\
\hline Outros & $10 \%$ & $54 \%$ \\
\hline Total & $\mathbf{1 0 0} \%$ & $\mathbf{1 0 0} \%$ \\
\hline
\end{tabular}

Já no caso das empresas brasileiras, os 54\% classificados como "outros" mostram que, sob o ponto de vista do aspecto analisado, o controller depende apenas da aprovação de outros executivos, que não são os principais das empresas, como, por exemplo, diretor financeiro e diretor administrativo, para receber aumentos espontâneos de salário. Considerando que as mencionadas funções são ocupadas por executivos que respondem ao principal líder da organização, pode-se entender que a função da área de controladoria como um mecanismo interno de governança corporativa não é tão clara nas empresas brasileiras como o é nas empresas norte-americanas, dada a influência que a dependência de executivos intermediários para a obtenção de melhorias salariais pode causar na performance do controller.

\subsection{Item 3: Responsabilidade pela contratação, promoção ou demissão do controller}

Uma das características fundamentais de uma área de controladoria é a de que o controller seja imparcial, isto é, que informe à alta administração acerca de todos os atos e fatos econômicos decorrentes de ações dos gestores organizacionais, mesmo que tenha que dar informações desfavoráveis sobre: a performance de determinada função, de determinado executivo ou colaborador, ainda que isso implique uma informação negativa desses profissionais, com reflexo direto em suas carreiras.

Dessa forma, a avaliação do nível de eficácia e neutralidade com a qual a área de controladoria exerce a sua função pode requerer uma análise dos fatores que possam afetar de alguma forma a desejável independência, que permita ao controller, líder desta área, executar seu trabalho da forma que se espera que o faça. Entre esses fatores destacam-se o nível hierárquico ao qual se subordina, que lhe permite aumentos de 
A Controladoria como um Mecanismo Interno de Governança Corporativa: Evidências de uma Survey Comparativa entre Empresas de Capital Brasileiro e Norte-Americano

Auster Moreira Nascimento, Márcia Bianchi, Paulo Renato Soares Terra

salário espontâneos, já discutidos nos itens 1 e 2, e que é responsável pela contratação, promoção ou demissão.

O resultado da pesquisa indica que, entre as empresas norte-americanas, em $78 \%$ dos casos a contratação, promoção ou demissão do responsável pela área de controladoria não podem ser decididas pela administração local isoladamente, como pode ser observado na Tabela 4. Essa constatação permite aferir que, nos casos observados, a alta administração busca proteger a função do controller contra eventuais dissabores causados por seu desempenho imparcial, justo e congruente com os interesses do principal ou de seu representante no ato de reportar com fidelidade e transparência as informações econômicas que traduzam as decisões tomadas pela administração local.

Entretanto, as constatações anteriormente expostas não podem ser estendidas às empresas brasileiras. Essa afirmação parte da observação dos dados da pesquisa, Tabela 4 , os quais indicam que em apenas $17 \%$ dos casos a contratação, promoção ou demissão do controller são decididas pela alta administração, aqui definida como representante do principal. Por outro lado, constatou-se, também, que em $60 \%$ dos casos das empresas brasileiras analisadas a contratação, promoção ou demissão são decididas a nível de diretoria local, ou seja, pelos diretores financeiros, administrativos e administrativo-financeiros. Não se pode afirmar que não existam nessas empresas mecanismos internos de boas práticas de governança corporativa, entretanto, se a independência funcional do controller for importante para isto, nos casos analisados a área de controladoria pode ter sua neutralidade afetada, bem como sua condição de mecanismo interno de governança corporativa.

Tabela 4 - Responsável pela Contratação, Promoção ou Demissão do Controller

\begin{tabular}{|c|c|c|}
\hline & Norte-Americana & Brasileira \\
\hline Gerente geral local ou equivalente & $16 \%$ & $9 \%$ \\
\hline Controller ou equivalente da matriz & $39 \%$ & $14 \%$ \\
\hline Gerente geral local e controller da matriz & $39 \%$ & $3 \%$ \\
\hline Principal executivo da corporação & $0 \%$ & $14 \%$ \\
\hline Outros & $6 \%$ & $60 \%$ \\
\hline Total & $\mathbf{1 0 0} \%$ & $\mathbf{1 0 0} \%$ \\
\hline
\end{tabular}


A Controladoria como um Mecanismo Interno de Governança Corporativa: Evidências de uma Survey Comparativa entre Empresas de Capital Brasileiro e Norte-Americano Auster Moreira Nascimento, Márcia Bianchi, Paulo Renato Soares Terra

Essa constatação parte do raciocínio análise de que a estabilidade do emprego do controller, nos mencionados $60 \%$ dos casos, depende de profissionais que ocupam funções hierárquicas posicionadas em níveis inferiores que seria desejável, tendo em vista ser o trabalho dos mencionados profissionais justamente os geradores das informações que são reportadas pela controladoria a alta administração. Isso pode ocorrer, nesses casos, sem a imparcialidade característica da missão do controller.

\subsection{Item 4: Atualização e alteração dos relatórios contábeis mensais e anuais}

Os relatórios contábeis são um dos instrumentos que a empresa dispõe para reduzir a assimetria informacional entre aquele que tem o seu controle, o principal, e aqueles que o administram, os agentes. Dessa forma, constitui-se em elemento básico de controle, que permite a transparência administrativa requerida pelas boas práticas de governança corporativa.

Assim, a área de controladoria tem nos relatórios contábeis a sua forma de conectar aqueles que detêm o controle da organização ao produto da ação gerencial praticada pelos gestores. Dada a importância desses demonstrativos, há de se esperar que os gestores, os agentes, não interfiram no processo de mensuração, que leva à obtenção dos mencionados relatórios.

A pesquisa revelou que em $58 \%$ das empresas norte-americanas pesquisadas (Tabela 5), os relatórios são enviados para o controller da matriz pela área de controladoria, sem que sejam admitidos quaisquer tipos de alterações promovidas pelos gestores responsáveis pelas atividades operacionais. Essa constatação reforça a função da controladoria como um mecanismo de governança corporativa. Já em 39\% das empresas dessa mesma origem, os relatórios contábeis são analisados e, se julgado necessário, alterados pela administração local antes de ser enviados para a matriz. A pesquisa não detectou quais tipos de alterações são admitidas. Embora isso possa, a princípio, ser interpretado como um fator não-positivo, por expor um indesejável poder da administração de eventualmente afetar a transparência das informações contidas nos relatórios contábeis, é possível inferir que as alterações processadas não causam danos às boas práticas de governança corporativa, posto que são consentidas pela área de controladoria. Esta, como pode ser visto nas Tabelas 2, 3 e 4, tem independência em 
A Controladoria como um Mecanismo Interno de Governança Corporativa: Evidências de uma Survey Comparativa entre Empresas de Capital Brasileiro e Norte-Americano

Auster Moreira Nascimento, Márcia Bianchi, Paulo Renato Soares Terra

relação à administração local no que se refere à divulgação detalhada dos resultados da organização. Sendo assim, poderia sanar ou divulgar os resultados das alterações se estes fossem danosos para a transparência administrativa.

Já nos casos das empresas brasileiras pesquisadas, observou-se que em apenas $29 \%$ delas o responsável direto pela gestão tem o poder de alterar os relatórios antes que eles sejam enviados para o conselho de administração ou para análise pela equipe do principal executivo da corporação, o que denota maiores cuidados com as boas práticas de governança corporativa. Isso também revela um aspecto curioso nessas empresas, ou seja, o controller, sob a perspectiva de subordinação, aumentos espontâneos de salário, demissão, entre outros, não teria o nível de independência suficiente em relação ao gestor responsável pelo processo de gestão, não permitindo a análise e eventual alteração dos dados dos relatórios contábeis por esse gestor antes que fossem enviados ao conselho de administração ou ao seu representante, tendo em vista que o monitoramento que a controladoria poderia exercer sob tal análise não permitiria o conforto da alta administração de que isso pudesse ser feito com isenção.

Tabela 5 - Relatórios Contábeis Mensais e Anuais

\begin{tabular}{|c|c|c|}
\hline & Norte-americana & Brasileira \\
\hline Atualizados e eventualmente alterados localmente & $39 \%$ & $29 \%$ \\
\hline Atualizados pela gerência geral local antes de seguir para a matriz & $45 \%$ & $21 \%$ \\
\hline Não são analisados localmente & $0 \%$ & $18 \%$ \\
\hline Primeiramente enviados para a matriz e depois analisados & $13 \%$ & $26 \%$ \\
\hline Outros & $3 \%$ & $6 \%$ \\
\hline Total: & $\mathbf{1 0 0 \%}$ & $\mathbf{1 0 0 \%}$ \\
\hline
\end{tabular}

\subsection{Análise Geral}

A análise isolada de pontos considerados importantes em termos de independência da área de controladoria no que se refere à divulgação dos atos e fatos administrativos destacados no gráfico 1, confirma que na maioria das empresas investigadas os fatores que poderiam eventualmente comprometer a posição de neutralidade do controller no exercício de sua função, uma vez determinados pela 
A Controladoria como um Mecanismo Interno de Governança Corporativa: Evidências de uma Survey Comparativa entre Empresas de Capital Brasileiro e Norte-Americano

Auster Moreira Nascimento, Márcia Bianchi, Paulo Renato Soares Terra

administração local, são controlados predominantemente pelas matrizes das empresas. Essa constatação é importante para reforçar a posição de independência da área de controladoria no exercício de suas atividades, posto que os mencionados fatores são relacionados à estabilidade do controller em sua posição, tendo a administração local pouco poder de interferir no progresso e na carreira desse profissional. Esse fato pode ser observado, principalmente, nas empresas norte-americanas, não se podendo deduzir, entretanto, as razões pelas quais essa evidência é menor nas empresas brasileiras do que nas norte-americanas.

Gráfico 1 - Eventos que Poderiam Afetar a Neutralidade do Controller e a sua Independência

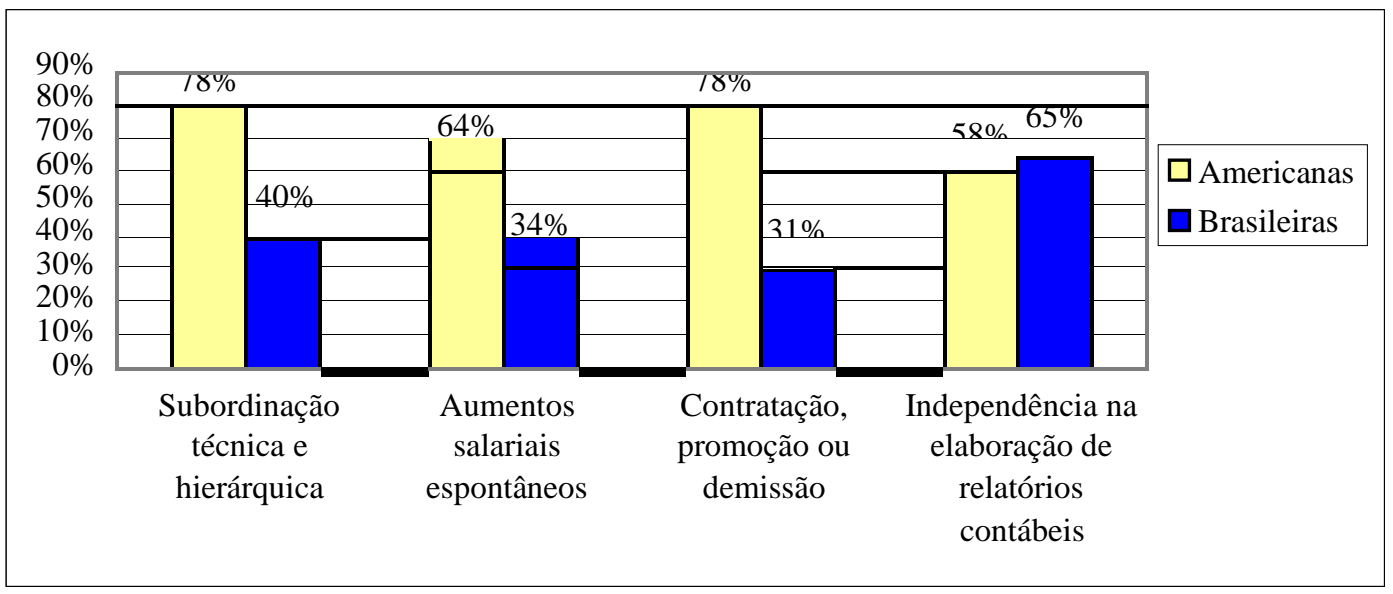

A interdependência entre as variáveis que podem contribuir para que o controller exerça suas funções com neutralidade em relação à administração local da empresa, também foi confirmada pelo teste qui-quadrado realizado (Tabela 6). O resultado apontou uma associação direta entre os fatores ligados à subordinação hierárquica desse profissional e sua independência para relatar com fidelidade os resultados decorrentes da atuação dos gestores da empresa no exercício de suas atividades. 
A Controladoria como um Mecanismo Interno de Governança Corporativa: Evidências de uma Survey Comparativa entre Empresas de Capital Brasileiro e Norte-Americano

Auster Moreira Nascimento, Márcia Bianchi, Paulo Renato Soares Terra

Tabela 6 - Associação entre a subordinação do controller, o responsável pelos aumentos salariais espontâneos e o responsável pela contratação, promoção ou demissão

\begin{tabular}{|c|c|}
\hline Estatística qui-quadrado & 16,439 \\
\hline Graus de liberdade & 1 \\
\hline Nível alfa & 0,05 \\
\hline Significância do qui-quadrado & 0,000 \\
\hline
\end{tabular}

\section{CONSIDERAÇÕES FINAIS}

As boas práticas de governança corporativa têm sua base na transparência das informações relativas às ações dos gestores na condução dos negócios. Entretanto, não se restringem a esse fator. Proprietários, governo, fornecedores e outros interessados pela empresa esperam também que os objetivos para ela estabelecidos sejam cumpridos com o adequado controle dos recursos consumidos para a geração de resultados e a segurança necessária para a manutenção de seus ativos. A governança corporativa tem relação, então, com uma empresa bem administrada, organizada e preparada para revelar a todos aqueles por ela interessados todas as nuances que envolvem sua administração.

Nesse contexto, essa pesquisa se concentrou em estudar a área de controladoria como um mecanismo de governança corporativa, buscando identificar traços que a credenciassem a ser considerada um fator de minimização dos conflitos de interesse entre os investidores da organização e seus administradores. Adicionalmente, procurou tratar de forma ampla a questão envolvendo os controles necessários para a preservação dos interesses dos investidores, isto é, segregando o controle organizacional em diferentes dimensões: a de controle operacional, a de controle físico-financeira e a prescritiva, no sentido de hierarquizá-las, para a melhor compreensão dos aspectos que envolvem a manutenção e a segurança de ativos e das operações de uma empresa.

Considerando o que foi apresentado no referencial teórico, conclui-se que a dimensão de controle prescritiva é elemento importante para as outras dimensões de controle, por proporcionar outros mecanismos de controle que asseguram a transparência administrativa, possibilitando a identificação e, por conseqüência, a minimização de 
A Controladoria como um Mecanismo Interno de Governança Corporativa: Evidências de uma Survey Comparativa entre Empresas de Capital Brasileiro e Norte-Americano Auster Moreira Nascimento, Márcia Bianchi, Paulo Renato Soares Terra

conflitos de interesse, e a área de controladoria é a responsável por sua implementação e monitoramento.

A dimensão de controle físico-financeira, apoiada na dimensão de controle prescritiva, tem como característica o registro de cada transação econômica realizada na organização, sendo dessa forma um instrumento para a manutenção da segurança de todos os seus ativos, proporcionando informações acuradas, tempestivas e íntegras dos seus resultados econômicos a todos os que têm interesse na empresa. A implementação e o monitoramento desses registros são realizados pela área de controladoria, que tem como uma de suas funções assegurar que cada recurso consumido esteja de acordo com os objetivos da empresa.

A dimensão de controle operacional, irrigada por outras dimensões de controle, compreende todo o processo decisório. É considerada um dos principais componentes de controle da organização, pois visa manter a integridade da empresa em seu ambiente. A área de controladoria, por monitorar o controle organizacional, deve estar envolvida em todas as fases do processo de gestão, e neste, por estabelecer os padrões de comportamento que se esperam dos gestores, pode também ocorrer a minimização dos conflitos de interesse entre os principais e agentes, por meio da promoção da transparência administrativa.

Os resultados dessa pesquisa sugerem que a área de controladoria possui condições, na maioria dos casos, para a manutenção de sua posição de independência em relação à administração local no processo de elaboração e divulgação das informações decorrentes dos atos e fatos administrativos. Isso possibilita promover a transparência administrativa, bem como a minimização da assimetria informacional entre principal e agente.

Um dos instrumentos que pode ser considerado um redutor da assimetria informacional entre aquele que detém a propriedade da organização e aqueles que a administram são os relatórios contábeis, elaborados pela área de controladoria. Para que isso aconteça, há a necessidade de que os gestores não interfiram no processo de elaboração dos relatórios. A pesquisa revelou um significativo nível de independência do controller na elaboração e no envio dos relatórios para a matriz, sem a interferência da 
A Controladoria como um Mecanismo Interno de Governança Corporativa: Evidências de uma Survey Comparativa entre Empresas de Capital Brasileiro e Norte-Americano

Auster Moreira Nascimento, Márcia Bianchi, Paulo Renato Soares Terra

administração local.

A área de controladoria, como demonstrado pela pesquisa, na maioria dos casos, atua com independência e neutralidade no exercício de sua função, podendo reportar com fidelidade e transparência as informações econômicas que traduzam as decisões tomadas pela administração local. Esse fato, verificado com maior intensidade nas empresas norte-americanas, indica que a contratação, promoção ou demissão do responsável por esta área não pode ser exercida pela administração local isoladamente, podendo isso ser determinante para a requerida neutralidade esperada de uma área que represente os interesses dos investidores.

Porém, ressalte-se, é possível inferir que a fonte que autoriza aumentos salariais espontâneos para o controller, responsável pela área de controladoria, pode influenciar negativamente a sua postura de independência na divulgação das informações contábeis em relação à administração local, dependendo de qual for. Nesse sentido, a pesquisa demonstrou que a interferência para a melhoria da posição salarial do controller é de origem externa à administração local, o que é positivo. Considerando isso um requisito para a manutenção da posição de neutralidade, entretanto, ela permitiu inferir apenas que essa condição favorável ocorre mais nas empresas norte-americanas do que nas brasileiras, embora não se possa afirmar que nestas últimas as condições para a manutenção de boas práticas de governança corporativa sejam afetadas pelo fato de que executivos que ocupam posições intermediárias entre o representante do principal e o executivo da administração local sejam os responsáveis pelas decisões envolvendo os mencionados benefícios financeiros.

Enfim, a pesquisa demonstrou que a área de controladoria pode ser considerada um mecanismo interno de governança corporativa, voltada ao provimento da transparência na divulgação dos atos e fatos administrativos, ampliando as possibilidades de redução da assimetria informacional e, consequentemente, a minimização dos conflitos de interesse. Conclui-se, entretanto, que essa função é desempenhada com maior nitidez nas empresas norte-americanas do que nas empresas brasileiras, instigando a realização de pesquisas especificas que investiguem a razão de tal diferença. 
A Controladoria como um Mecanismo Interno de Governança Corporativa: Evidências de uma Survey Comparativa entre Empresas de Capital Brasileiro e Norte-Americano

Auster Moreira Nascimento, Márcia Bianchi, Paulo Renato Soares Terra

\section{REFERÊNCIAS}

ALCHI AN, A. e DEMSETZ, A. 1972. Production, I nform at ion Costs, and Economic Organization. In: The American Ecomonic Review, p. 777- 795.

ALMEI DA, F.G. 2001. Governança Corporativa no Brasil: criação de valor com base na gestão corporativa - um estudo de caso do setor de telecomunicações. Rio de Janeiro, RJ. Dissertação de Mestrado. Pontifícia Universidade Católica do Rio de Janeiro PUC- RJ, 149 p.

ALMEI DA, L.B.; PARI SI, C. e PEREI RA, C.A. 2001. Controladoria. In: Controladoria: um a abordagem da gestão econômica - GECON. Armando Catelli (coordenador). São Paulo, At las, p. 343- 355.

BECHT, M.; BOLTON, P. e RÖELL, A. 2002. Corporate Governance and Control. In: National Bureau of Economic Research. Working Paper no 9371.

BERLE, A. A. e MEANS, G. C. 1984. A Moderna Sociedade Anônima e a Propriedade Privada. São Paulo, Abril Cultural, 335 p.

CARVALHO, A.G. 2002. Governança Corporativa no Brasil em Perspectiva. In: Revista de Administração. São Paulo, 37 (3): 19- 32.

Cia, J.C.; Guarita, C. I. e Cia, J.N.S. 2002. O Duplo Papel do Investidor Institucional: influenciador do Corporate Governance e gestor de carteiras. In: Encontro Nacional dos Programas de Pós-Graduação em Administração - ENANPAD, 26, Salvador/ Bahia, 2002.

COASE, R. 1937. The Nature of the Firm. In: Econômica, 4: 386 - 405

CVM - Comissão de Valores Mobiliários. Recomendações da CVM sobre Governança Corporativa. Junho de 2002.

DUBEUX, R.R. 2001. O Novo Mercado da Bovespa e a Governança Corporativa. São Paulo, SP. Dissertação de Mestrado. EAESP/ FGV, 2001, 116 p.

HI TT, A.M.; I RELAND, R.D. e HOSKI SSON, R. E. 2003. Administração Estratégica: competitividade e globalização. São Paulo, Pioneira Thom son Learning, 121 p.

IBGC - Instituto Brasileiro de Governança Corporativa. Código das Melhores Práticas de Governança Corporativa. Disponível em: http: / / www.ibgc.org.br, acesso em 20/ 05/ 2004.

Jensen M. e Meckling, W. 1976. Theory of the firm: Managerial behavior, agency cost, and ownership structure. In: Journal of Financial Economics. p. 305- 360. 
LODI, J.B. 2000. Governança Corporativa: o governo da empresa e o conselho de administração. Rio de Janeiro, Campus, 190 p.

MI LGROM, P. e ROBERTS, J. 1992. Economics, Organizacional and Management. New Jersey, Prentice- Hall, $621 \mathrm{p}$.

REA, L.M. e PARKER, R.A. 2002. Metodologia de Pesquisa: do planejamento a execução. São Paulo, Pioneira Thom son Learning, 296 p.

Stevenson, W.J. 2001. Estatística Aplicada à Administração. São Paulo, Harper e Row do Brasil, $495 \mathrm{p}$.

TUNG, N.H. 1993. Controladoria Financeiras das Empresas: uma abordagem prática. $8^{\mathbf{a}}$ ed. São Paulo, Edições Universidade - Empresa - Editora da Universidade de São Paulo, $435 \mathrm{p}$.

WI LLI AMSON, O. 1985. The Economic Institutions of Capitalism: firms, markets, relational contracting. New York, The Free Press, pp. 442- 444.

Data de Submissão: 19/07/2007

Data de Aceite: 27/08/2007 